\title{
Comparison on cognitive performance among schoolchildren born prematurely according to the presence of intracranial hemorrhage in the neonatal period
}

Marcia Salim de Martino 1

https://orcid.org/0000-0003-0694-1576

Leandro Lopes Fernandes Alves 2

https://orcid.org/0000-0002-2024-0955

Cristina Ortiz Sobrinho 3

https://orcid.org/0000-0002-6925-4346

Adauto Dutra Moraes Barbosa 4

https://orcid.org/0000-0003-2841-9877

${ }^{1}$ Serviço de Psiquiatria da Infância e Adolescência. Hospital Universitário Antônio Pedro. Universidade Federal Fluminense. Rua Marques de Paraná, 303. Centro. Niterói, RJ, Brasil. CEP: 24.030-900. E-mail: marciademartino@yahoo.com.br

2-4 Departamento Materno-Infantil. Faculdade de Medicina. Universidade Federal Fluminense. Niterói, RJ, Brasil.

\begin{abstract}
Objectives: to compare the cognitive performance of schoolchildren born prematurely according to the presence of intracranial hemorrhage (ICH) during the neonatal period.

Methods: a cross-sectional cohort study of schoolchildren between the ages of 6-8 years old, born prematurely with or without a history of neonatal ICH. Between January and December 2015, some children were followed up at the outpatient clinic of a tertiary hospital and underwent a cognitive evaluation by using the Wechsler Intelligence Scale for Children, Third Edition (WISC-III) and they were divided into two groups: those with no history of ICH (control group) and those with ICH (case group), confirmed by a transfontanelar ultrasound in the prenatal period.

Results: 39 schoolchildren were included, 21 cases and 18 controls. There was no difference in gestational age or chronological age at evaluation between the groups. Also there was no significant difference in subtest scores between the groups.

Conclusions: WISC-III evaluated the cognitive performance in children, born preterm, aged 6-8 years old, and had neonatal ICH did not differ from those of their peers without a history of ICH. These findings suggest that, in preterm infants, a neonatal diagnosis of ICH may not be associated with cognitive performance at school age and this should be investigated through a longitudinal study.
\end{abstract}

Key words Preterm birth, Intracranial hemorrhage, Intelligence

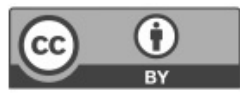




\section{Introduction}

The consequences of prematurity in children development are now recognized as important indicators of impaired cognitive development, 1,2 especially at school age, when academic demands become greater. ${ }^{3}$ Early identification and intervention are needed to take advantage of the greater neuroplasticity observed in the neonatal period. 4

There is substantial evidence that children born prematurely have a higher prevalence of cognitive impairment, as moderate to severe difficulties in school performance and poor executive function has been obseved, 5 which persists into adolescence and adulthood when these children are compared to their peers who were born full term.2,5,6

Among several neonatal complications associated with prematurity, intracranial hemorrhage (ICH) is often cited in the literature as a predictor of abnormal neurological development and reduced cognitive competence.6-8

Attributed to immaturity of the germinal matrix, $\mathrm{ICH}$, especially intraventricular hemorrhage (IVH), is the leading cerebral complication observed in preterm infants in the first 24-48 hours of life, particularly in those with a birth weight $<1,500 \mathrm{~g}$. The mechanism of ICH is multifactorial, 9 it involves a combination of vascular and structural immaturity, hemodynamic factors, and, possibly, inflammatory and genetic factors that have to be fully investigated. 10

The severity of ICH has been evaluated by the classification proposed by Papile et al.11 In this scheme, grade I hemorrhage is confined to the germinal matrix; grade II hemorrhage extends to the lateral ventricle, without dilatation; grade III hemorrhage is associated with the presence of dilatation in addition to grade II findings; and grade IV also involves intraparenchymal hemorrhage. 10

However, it is still unclear whether those children who were born prematurely and had ICH in the perinatal period will exhibit poor performance on cognitive evaluation when they reach school age (the stage of development at which problems related to cognition are most easily detected).

The use of standardized, culturally adapted, and validated instruments for assessment of child development, such as the Wechsler Intelligence Scale for Children, Third Edition (WISC-III), 12 has been recommended as a strategy to promote child health. The WISC-II is one of the most widely and respected instruments used worldwide, adapted for multiple cultures and countries. It was developed for clinical, psycho-educational, and research settings alike, and gives possible detailed evaluation of cognitive capacity in children. ${ }^{12-14}$

Identifying whether ICH predicts alterations in the cognitive assessment among children born prematurely, justifying the interest for further investigation on this issue. Within this context, the objective in this present study was to compare the cognitive performance of schoolchildren who were born prematurely according to the presence or absence of ICH during the neonatal period.

\section{Methods}

This is a cross-sectional study on schoolchildren aged 6-8 years old who were born at a gestational age $<37$ weeks, underwent transfontanelar ultrasound in the neonatal period, and were later followed at the High-Risk Newborn Follow-up Clinic at a tertiary referral center. The study was conducted at Hospital Universitário Antônio Pedro (HUAP), Niterói, Brazil, from January to December 2015.

The schoolchildren recruited for the study were divided into two groups: a control group (CG) who were born prematurely and did not present $\mathrm{ICH}$; and a case group (HG) who were born prematurely and presented ICH. Children who were clinically stable and able to maintain the necessary level of attention to perform the required tasks of the evaluation instrument were deemed eligible for inclusion. Children with genetic syndromes, congenital malformations, visual and/or hearing impairment, severe enough to preclude testing with the study instrument were excluded, as were those who developed any disease (neurological or other) that could compromise the central nervous system between the perinatal period and school age.

At the time of the assessment, all the participants were regularly attending school, with the majority (95\%) of the children who were grade consistent with their chronological age.

The sampling strategy was composed of consultations and children's medical records were analyzed with the purpose of obtaining information about pathological conditions recorded by the neonatologist during hospitalization at the HUAP neonatal intensive care unit. The children's assessment was conducted in two sessions. The first session was reserved for the completion of a questionnaire to ascertain each participant's profile, as well as to have the first encounter between the psychologist with the child and parents. During the second session, the evaluation instrument was administered to assess cognitive performance. This was done individually, in a single session, at the Outpatient Child 
Development Clinic at the Child and Adolescent Psychiatry Department. The responses were recorded in protocols of the forms itself for further analysis and interpretation.

The WISC-III is an instrument designed to evaluate the intelligence of children aged 6 to 16 years 11 months old, which enables the construction of the participant's cognitive profile based on a model that emphasizes verbal and nonverbal skills. ${ }^{12}$ It is organized into two scales: Verbal (comprising the subtests on Information, Similarities, Arithmetic, Vocabulary, Comprehension, and Digit Span) and Performance or nonverbal (comprising the subtests on Picture Completion, Coding, Picture Arrangement, Block Design, Object Assembly, and Symbol Search). The weighted scores are used to obtain the full-scale intelligence quotient (FSIQ), resulting from two subtests groups: the verbal score, which result in the Verbal IQ (VIQ), and the Performance score, which results in the Performance IQ (PIQ). The subtests also provide four "Factor Indexes" associated with specific competences: Verbal Comprehension, Perceptual Organization, Freedom from Distractibility, and Processing Speed. The results are expressed as the intelligence quotient (IQ), and distributed in seven categories: very superior $(\geq 129)$, superior $(120-128)$, high average (110-119), average (90-109 points), low average (80-89), and borderline (70-79); scores below 70 suggest intellectual impairment. 12

The WISC-III was administered by only one examiner, and the result was reviewed immediately after by another examiner. Both were psychologists with more than 15 years of experience in the field of child development. At the time of the study, although the Wechsler Intelligence Scale for Children, Fourth Version (WISC-IV)14 had already been published, the decision was made to use the WISC-III, as it was validated to be used in Brazil until 2018 and it was already utilized at the Child and Adolescent Psychiatry Department.

The statistics for gestational age and age at cognitive assessment, including means, standard deviations, and confidence intervals, and the differences between groups were evaluated by Student's $t$-test. The ICH grades were presented in frequency forms. To evaluate the weighted scores for each subtest in both study groups, the Mann-Whitney test was used to compare after testing for normality of distribution by the Shapiro-Wilk test. The significance level was set at $p<0.05$.

The statistical analyses were performed by using the IBM-SPSS Version 18.0 (SPSS Inc.C), Chicago, Illinois).
This study was approved by the Ethics Research Committee at the Faculdade de Medicina da Universidade Federal Fluminense, document number $1,103,474$

\section{Results}

One hundred and forty-one schoolchildren who were born preterm and aged 6-8 years old in 2015 were enrolled to participate in the study. Of these, $27 \mathrm{met}$ one or more exclusion criteria, 71 were lost to follow-up, and four did not want to participate of the study. The final sample of the study was composed of 39 children, 21 were born premature and presented $\mathrm{ICH}$, case group (HG), and 18 who did not have $\mathrm{ICH}$, and control group (CG), as shown in Figure 1

According to the classification of Papile et al.,11 the $21 \mathrm{HG}$ participants were distributed as follows: 6 (28.6\%) presented ICH grade I, 9 (42.9\%) had ICH grade II, and $3(14.2 \%)$ children represented grade III as the participants with the same grade and alike those with ICH grade IV.

The mean values and its dispersion indicator related to the control and case groups, are in relation to gestational age and age at cognitive assessment as shown in Table 1 .

The assessment results performed by the WISCIII in examining the intelligence coefficients and to understand the children's intellectual function in the control and case groups are shown in Tables 2 and 3.

Considering that the Wechsler scales have a mean score of 10 and the standard deviation is 3, the results obtained show the weighted scores above 10 in all the subtests in both groups, except for the Information subtest of the Verbal scale, which had a mean score of $<10$ weighted points in the case group. In both groups, the best performance was obtained in the Figure Completion subtest of the Performance scale. The lowest values were found for the Information and Symbol Search subtests in the case group and for the Comprehension subtest in the control group, suggesting greater homogeneity in participants' performance. In contrast, the subtests with the highest standard deviation were Vocabulary (verbal scale) and Block Design (Performance scale) in the case group and the Arithmetic, Vocabulary, and Digit Span subtests of the Verbal scale in the control group. No statistically significant difference was found in the subtests between the two groups.

Table 3 presents the FSIQ, VIQ, and PIQ values and WISC-III Factor Indexes. The two groups obtained average and above-average results as compared to the normative sample mean, where a 
Figure 1

Flowchart on the selection of the study participants. Niterói-RJ, 2015.

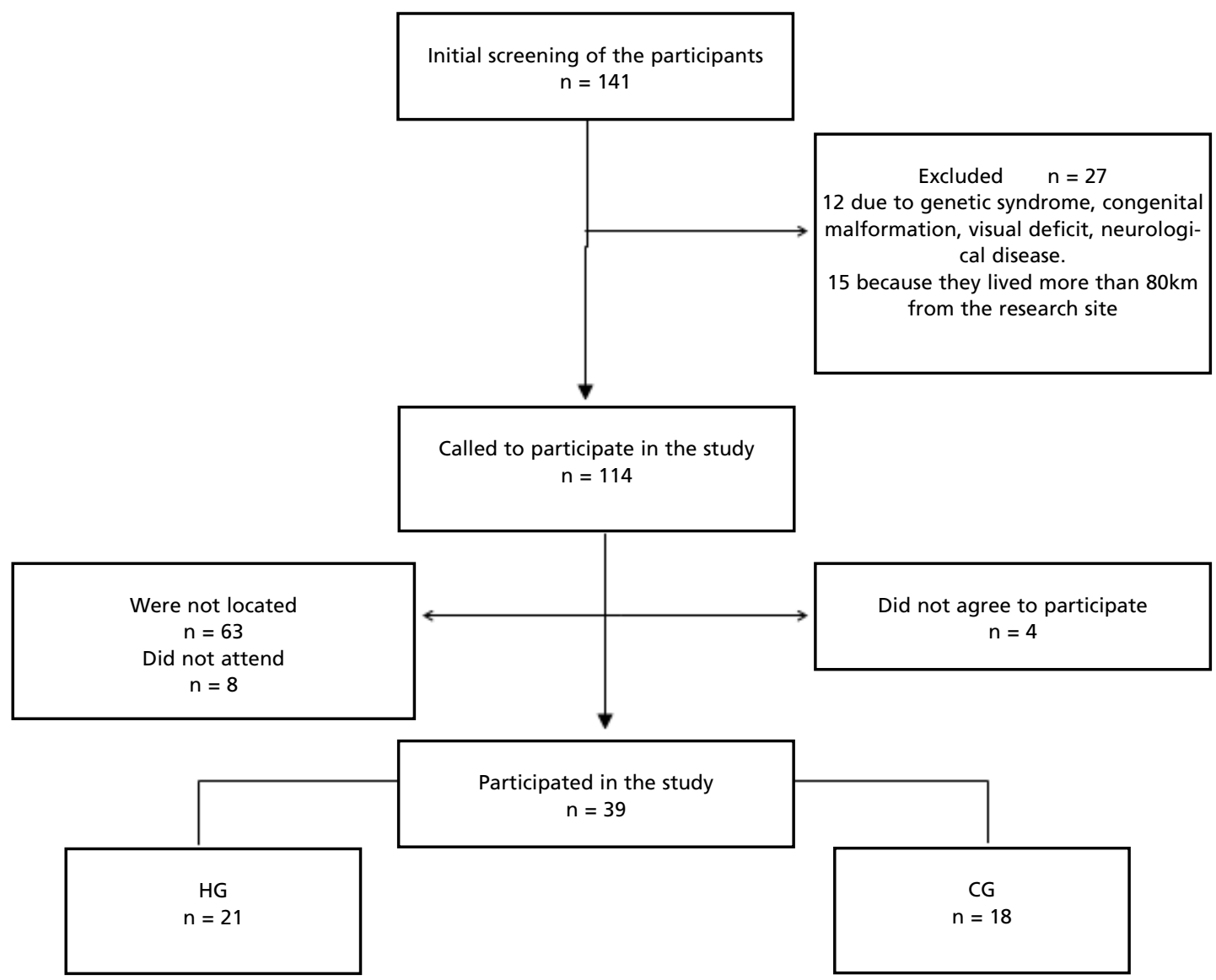

$\mathrm{HG}=$ Case group; $\mathrm{CG}=$ Control group .

score of 100 on any of the three scales defines the average performance of a child at a given age.

The control group achieved higher VIQ, PIQ, and FSIQ mean scores, and performed better in the Verbal Comprehension and Perceptual Organization dimensions, when compared to the case group. In case-group participants, the PIQ mean was higher than the VIQ mean; a similar discrepancy was found in the Verbal Comprehension and Perceptual Organization factor indexes (VCIQ > POIQ). The control-group children exhibited similar performance in the Verbal Comprehension, Perceptual Organization, and Processing Speed dimensions. Among the case-group children, the best performance was achieved in the Processing Speed dimension. No significant differences between the groups were observed for any of the scores (Table 3).

Table 4 shows the percentages of the WISC-III scores in relation to the IQ categories between the groups. In both groups, most of the participants fell into the average category, followed by the highaverage category in relation to FSIQ. Pooling as classifications, it was observed that $95.5 \%$ of the case-group children were classified as average, highaverage, or superior, while only $9.5 \%$ had belowaverage intellectual development.

Regarding to verbal and nonverbal performance, most of the children in both groups were classified in the average category. Overall, 18 children $(85.7 \%)$ in the case group achieved an average or highaverage score, $2(9.5 \%)$ had low-average scores, and $1(4.8 \%)$ was classified as borderline for VIQ. In relation to PIQ, $100.0 \%$ of the children in the case group were classified as average or high average. In the control group, 16 children (88.9\%) achieved average or above-average performance, while 2 
Table 1

\begin{tabular}{|c|c|c|c|c|c|}
\hline \multirow[t]{2}{*}{ Variables } & \multicolumn{2}{|c|}{ CG $(n=18)$} & \multicolumn{2}{|c|}{ HG $(n=21)$} & \multirow[t]{2}{*}{$p$} \\
\hline & $\bar{X} \pm S D$ & $\mathrm{Cl} 95 \%$ & $\bar{X} \pm S D$ & $\mathrm{Cl} 95 \%$ & \\
\hline Gestational age (weeks) & $31.17 \pm 3.10$ & $30.30-32.04$ & $31.38 \pm 3.45$ & $30.54-32.23$ & 0.715 \\
\hline Age at the cognitive assessment (years) & $7.63 \pm 0.18$ & $7.28-7.99$ & $7.28 \pm 0.65$ & $6.98-7.57$ & 0.110 \\
\hline
\end{tabular}

$\mathrm{SD}=$ standard deviation; $\mathrm{Cl} 95 \%=95 \%$ confidence interval; $C \mathrm{G}=$ control group; $\mathrm{HG}=$ case group; $p<0,05 ;$ Student's $t$-test.

Table 2

Results obtained in the WISC-III subtests of children in the CG and HG. Niterói-RJ, 2015.

\begin{tabular}{|c|c|c|c|}
\hline Groups & CG & HG & $p$ \\
\hline Subtests & $\bar{X} \pm S D$ & $\bar{X} \pm S D$ & \\
\hline Information & $9.52 \pm 1.77$ & $10.05 \pm 2.41$ & 0.977 \\
\hline Similarities & $11.90 \pm 2.40$ & $11.94 \pm 2.33$ & 0.932 \\
\hline Arithmetic & $11.61 \pm 2.47$ & $10.55 \pm 3.11$ & 0.054 \\
\hline Vocabulary & $10.52 \pm 3.54$ & $11.38 \pm 3.14$ & 0.977 \\
\hline Comprehension & $10.52 \pm 2.65$ & $11.16 \pm 1.79$ & 0.820 \\
\hline Digit span & $11.00 \pm 2.77$ & $11.94 \pm 3.18$ & 0.403 \\
\hline Figure completation & $12.33 \pm 2.12$ & $12.66 \pm 2.08$ & 0.864 \\
\hline Coding & $11.47 \pm 2.04$ & $11.55 \pm 2.59$ & 1.000 \\
\hline Picture arrangement & $10.04 \pm 2.67$ & $10.04 \pm 2.54$ & 0.561 \\
\hline Block design & $10.23 \pm 3.03$ & $10.83 \pm 2.59$ & 0.523 \\
\hline Object assembly & $10.33 \pm 2.55$ & $10.27 \pm 2.53$ & 0.383 \\
\hline Symbol search & $11.38 \pm 1.83$ & $11.55 \pm 2.59$ & 1.000 \\
\hline
\end{tabular}

WISC III = Wechsler Intelligence Scale for Children-3rd edition; CG = control group; HG = case group; SD = standard deviation; $p<0.05$; Student's $t$-test.

Table 3

Total, Verbal and Execution IQ scores and the WISC-III Factorial Indexes in the CG and HG. Niterói-RJ, 2015.

\begin{tabular}{lccc}
\multicolumn{1}{c}{ Groups } & CG & HG & P \\
\cline { 2 - 4 } WISC-III & $\bar{X} \pm$ SD & $107.33 \pm 12.14$ & 0.877 \\
\hline Full scale IQ & $103.54 \pm 11.71$ & $106.27 \pm 19.09$ & 0.822 \\
Verbal IQ & $105.00 \pm 9.69$ & $107.83 \pm 12.78$ & 0.800 \\
Performance IQ & $106.23 \pm 9.26$ & $106.16 \pm 11.44$ & 0.526 \\
Verbal comprehension & $101.95 \pm 10.63$ & $106.11 \pm 11.27$ & 0.855 \\
Perceptual organization & $103.71 \pm 10.80$ & $105.83 \pm 17.44$ & 0.612 \\
Freedom from distractibility & $105.76 \pm 12.80$ & $106.94 \pm 15.51$ & 0.821 \\
Processing speed & $106.28 \pm 9.29$ & & \\
\end{tabular}

WISC III = Wechsler Intelligence Scale for Children-3rd edition; CG = control group; HG = case group; SD = standard deviation; IQ = intelligence quotient; $p<0.05$; Student's $t$-test. 
(5.6\%) had unsatisfactory performance, one in the low average category and the other in the borderline category (Table 4)

Table 4

Percentages on the WISC-III scores for the different categories of Total IQ, Verbal IQ and Execution IQ for CG and HG. Niterói-RJ, 2015.

\begin{tabular}{|c|c|c|c|c|c|c|c|}
\hline \multirow[t]{2}{*}{ IQ categories * } & \multirow[t]{2}{*}{ IQ Indexes* } & \multicolumn{3}{|c|}{ CG } & \multicolumn{3}{|c|}{ HG } \\
\hline & & QVI & IQE & TIQ & QVI & IQE & TIQ \\
\hline Far superior & $(\geq 129)$ & 0.0 & 0.0 & 0.0 & 5.6 & 5.6 & 0.0 \\
\hline Higher & $(120-128)$ & 0.0 & 4.8 & 4.8 & 0.0 & 11.1 & 16.7 \\
\hline Average higher & $(110-119)$ & 38.1 & 33.3 & 28.6 & 38.9 & 33.3 & 33.3 \\
\hline Average & $(90-109)$ & 47.6 & 61.9 & 57.1 & 44.4 & 44.4 & 44.4 \\
\hline Lower average & $(80-89)$ & 9.5 & 0.0 & 9.5 & 5.6 & 5.6 & 0.0 \\
\hline Bordering & $(70-79)$ & 4.8 & 0.0 & 0.0 & 5.6 & 0.0 & 5.6 \\
\hline
\end{tabular}

* Reprinted from Wechsler. 12

WISC III = Wechsler Intelligence Scale for Children-3rd edition; CG = control group; HG = case group; IQ = intelligence quotient; $\mathrm{QVI}=$ quotient of verbal intelligence; $\mathrm{IQE}=$ intelligence quotient execution; TIQ = total intelligence quotient.

\section{Discussion}

Prematurity and the presence of ICH in the neonatal period constitute risk factors for development at different stages of later life, but especially during school age, when cognitive difficulties become more noticeable. ${ }^{3}$ However, in this present study, the vast majority of the schoolchildren in both groups, with and without a history of neonatal $\mathrm{ICH}$, exhibited average intelligence, indicating adequate intellectual performance. Regarding to cognitive performance, the scores were within the mean range as compared to the normative sample, where a score of 100 on any of the three WISC-III scales defines the average performance of a child at a given age. ${ }^{12}$

Performance on the FSIQ, VIQ, PIQ, and Factor Indexes was not associated with $\mathrm{ICH}$, although comparison of the two groups showed numerically poorer FSIQ, VIQ, PIQ, Verbal Comprehension, and Perceptual Organization performance in the case group.

Consistent with the well-established finding that preterm children with grade I and II ICH tend to recover well but may present developmental impairments when compared to children without this condition, $8,15,16$ the WISC-III results showed a small discrepancy, as for the children in the case group, they had lower VIQ, PIQ, and FSIQ scores compared to the controls, although the children in both groups had a normal intellectual level.
There was no widespread impairment of cognitive function in any of the study participants, contradicting the findings of a previous study. 17 Only in the Information subtest, which evaluates organization, memory efficiency, and level of knowledge, did the participants in the case group achieve a mean score $<10$ weighted points. No relevant changes were observed in the other cognitive functions assessed. Other authors 1,2 have reported specific cognitive impairments in children with this condition; attention, memory, visuomotor skills, dyscalculia, and deficits in processing speed and executive function are among those most often cited.

A study conducted in France found that $68 \%$ of children born at a gestational age $<32$ weeks had normal cognitive performance at age $6-10$ years old, $18 \%$ had minor impairments, and $14 \%$ had major disorders. 18 These results are partially consistent with those of the present sample. A review of children born at a gestational age $<33$ weeks found that their IQ scores at age 5-11 years old were in the average range, 19 a finding similar to those of the present study.

A cohort investigated the association between ICH severity and cognitive development in children with birth weight $<1000 \mathrm{~g}$ and gestational age $<28$ weeks at 8 years of age found cerebral palsy, motor impairments, and major sensorineural deficits in those with a history of grade IV ICH, and worsening performance on cognitive functioning domains with 
increasing ICH severity. These children with severe ICH represented a small portion of the sample, and no significant impairment was observed in those with lower-grade of ICH.20 These findings are similar to those of the present sample, especially given that these were preterms born $>31$ weeks; those born at a gestational age $<30$ weeks are more vulnerable and have a worse prognosis in the presence of $\mathrm{ICH}$, because in addition to the risks of prematurity itself, they are at the peak stage of neovascularization and thus have higher odds of hemorrhage. 9

Few follow-up studies on preterms with ICH have been found in literatures.7,15,16 Among these few, most have been medium and long-term investigations and used the WISC-III to evaluate cognitive performance. Considering this literature gap, we expanded our theoretical framework to include studies that did not approximate our population as closely, such as those performed with preterms younger than 28 weeks and a chronological age older or younger than that in our sample. $6-8,15-18$

The greatest limitation of our research was the lack of a longitudinal study that would have allowed evaluation of changes in participants' cognitive development over time. We used a sample of children who had been admitted to a neonatal intensive care unit after birth and later referred to an outpatient clinic; however, most never returned for followup, which necessitated the use of a convenience sampling strategy. This, together with the small sample size, may have hindered detection of statistical differences.

\section{References}

1. Costa DS, Miranda DM, Burnett AC, Doyle LW, Cheong JLY, Anderson PJ, Victorian Infant Collaborative Study Group. Executive Function and Academic Outcomes in Children Who Were Extremely Preterm. Pediatrics. 2017; 140 (3): e20170257.

2. Haebich KM, Willmott C, Ellis R, Burnett AC, Scratch SE, Pascoe L, Spencer-Smith MM, Cheong JLY, Inder TE, Doyle LW, Thompson DK, Anderson PJ. Goal Setting Deficits at 13 Years in Very Preterm Born Children. J Int Neuropsychol Soc. 2018; 24 (4): 372-81.

3. Johnson S, Marlow N. Early and long-term outcome of infants born extremely preterm. Arch Dis Child. 2017; 102 (1): $97-102$.

4. Ranasinghe S, Or G, Wang EY, Ievins A, McLean MA, Niell CM, Chau V, Wong PK, Glass HC, Sullivan J, McQuillen PS. Reduced Cortical Activity Impairs Development and Plasticity after Neonatal Hypoxia Ischemia. J Neurosci. 2015; 35 (34): 11946-59.
The favorable outcomes obtained in the cognitive performance assessment in this sample may be attributable to the follow-up care received by the children who attended our outpatient clinic at least until 24 months of age, which is provided by a multidisciplinary team consisted of a neonatologist, nurse, dietitian, and psychologist and includes guidance on essential developmental stimulation for parents or guardians. Interventions such as playing, reading, and tactile and/or motor stimulation during the early childhood period ( $0-3$ years) can help improve neurocognitive function throughout life. ${ }^{21}$

In this present study, children at age 6-8 years old, the WISC-III measures cognitive performance in preterm children who had neonatal ICH did not differ from those of their peers without a history of ICH. Within our context, these findings suggest that a neonatal diagnosis of $\mathrm{ICH}$ in preterms may not be associated with cognitive performance at school age, in which this should be investigated through a longitudinal study.

\section{Author's contribution}

Martino MS and Barbosa ADM contributed in the concept of the article. Alves LLF and Martino MS performed the data collecting. The statistic analysis was carried out by Sobrinho CO. All the authors approved the final version of the manuscript and are responsible for the context of the article.

5. Rogers EE, Hintz SR. Early neurodevelopmental outcomes of extremely preterm infants. Semin Perinatol. 2016; 40 (8): 497-509.

6. Vollmer B, Roth S, Baudin J, Stewart AL, Neville BG, Wyatt JS. Predictors of long-term outcome in very preterm infants: gestational age versus neonatal cranial ultrasound. Pediatrics. 2003; Nov; 112 (5): 1108-14.

7. Bolisetty S, Dhawan A, Abdel-Latif M, Bajuk B, Stack J, Lui K; New South Wales and Australian Capital Territory Neonatal Intensive Care Units' Data Collection: Intraventricular hemorrhage and neurodevelopmental outcomes in extreme preterm infants. Pediatrics. 2014; 133: 55-62.

8. Mercier CE, Dunn MS, Ferrelli KR, Howard DB, Sol 1RF; Vermont Oxford Network ELBW Infant Follow-Up Study Group. Neurodevelopmental outcome of extremely low birth weight infants from the Vermont Oxford network: 1998-2003. Neonatol. 2010; 97 (4): 329-38. 
9. Ballabh P. Intraventricular hemorrhage in premature infants: mechanism of disease. Pediatr Res. 2010; 67 (1): 1 8.

10. Bhandari V, Bizzarro MJ, Shetty A, Zhong X, Page GP, Zhang H, Ment LR, Gruen JR; Neonatal Genetics Study Group. Familial and genetic susceptibility to major neonatal morbidities in preterm twins. Pediatrics. 2006; 117 (6): 1901-6.

11. Papile LA, Burstein J, Burstein R, Koffler H. Incidence and evolution of subependymal and intraventricular hemorrhage: a study of infants with birth weights less than 1.500 gm. J Pediatr. 1978; 92 (4): 529-34.

12. Wechsler D. WISC - III: Escala de inteligência Wechsler para crianças: Manual, 3 ed. Adaptação e padronização de uma amostra Brasileira, 1 ed. Figueiredo, LMV. São Paulo: Casa do Psicólogo; 2002.

13. Cunha JA. Psicodiagnóstico-V. 5 ed. Porto Alegre: Artes Médicas; 2000.

14. Wechsler, D. Escala Weschsler de inteligência para crianças: WISC-IV. Manual Técnico. 4 ed. Tradução do manual original Maria de Lourdes Duprat. São Paulo: Casa do Psicólogo; 2013.

15. Payne AH, Hintz SR, Hibbs AM, Walsh MC, Vohr BR, Bann CM, Wilson-Costello DE; for the Eunice Kennedy Shriver National Institute of Child Health and Human Development Neonatal Research Network. Neurodevelopmental outcomes of extremely low-gestational-age neonates with low-grade periventricular-intraventricular hemorrhage. JAMA Pediatrics. 2013; 167 (5): 451-9.

16. Reubsaet P, Brouwer AJ, van Haastert IC, Brouwer MJ, Koopman C, Groenendaal F, de Vries LS. The impact of low-grade germinal matrix-intraventricular hemorrhage on neurodevelopmental outcome of very preterm infants. Neonatol. 2017; 112: 203-10

17. Marlow N, Wolke D, Bracewell MA, Samara M, EPICure Study Group. Neuro- logic and developmental disability at six years of age after extremely preterm birth. N Engl J Med. 2005; 352 (1): 9-19.

Received on April 27, 2018

Final version presented on January 29, 2019

Approved on March 25, 2019
18. Brevaut-Malaty V, Busuttil M, Einaudi MA, Monnier AS, D'Ercole C, Gire C. Longitudinal follow-up of a cohort of 350 singleton infants born at less than 32 weeks of amenorrhea: neurocognitive screening, academic outcome, and perinatal factors. Eur J Obstet Gynecol Reprod Biol. 2010; 150 (1): 13-8.

19. Johnson S. Cognitive and behavioural outcomes following very preterm birth. Seminars in Fetal and Neonatal Service. 2007; 12 (5): 363-73.

20. Sherlock RL, Anderson PJ, Doyle LW, Victorian Infant Collaborative Study Group: Neurodevelopmental sequelae of intraventricular haemorrhage at 8 years of age in a regional cohort of ELBW/very preterm infants. Early Hum Dev. 2005; 81: 909-16.

21. Santos LM, Santos DN, Bastos ACS, Assis AMO, Prado MS, Barreto ML. Determinants of early cognitive development: hierarchical analysis of a longitudinal study. Cad Saúde Pública. 2008; 24 (2): 427-37.

27. Ferreira RAB, Benicio MHDA. Obesidade em mulheres brasileiras: associação com paridade e nível socioeconômico. Rev Panam Salud Pública. 2015; 37 (4/5): 337-42.

28. Kac G, Nucci LB, Spyrides MH, Duncan BB, Schmidt MI. Evaluation of the ability of a Latin American gestational weight curve to predict adverse pregnancy outcomes. Int $\mathbf{J}$ Gynaecol Obstet. 2009; 106 (3): 223-6.

29. Reichenheim ME, Coutinho ESF. Measures and models for causal inference in crosssectional studies: arguments for the appropriateness of the prevalence odds ratio and related logistic regression. BMC Med Res Methodol. 2010; 10 (66): 1-12.

30. McGowan CA, McAuliffe FM. Maternal nutrient intakes and levels of energy underreporting during early pregnancy. Eur J Clin Nutr. 2012; 66 (8): 906-13. 